\title{
Photocontrolled DNA minor groove interactions of imidazole/pyrrole polyamides
}

\author{
Sabrina Müller ${ }^{1}$, Jannik Paulus ${ }^{1}$, Jochen Mattay ${ }^{2}$, Heiko Ihmels ${ }^{3}$, Veronica I. Dodero ${ }^{1}$ \\ and Norbert Sewald ${ }^{*}$
}

\section{Full Research Paper}

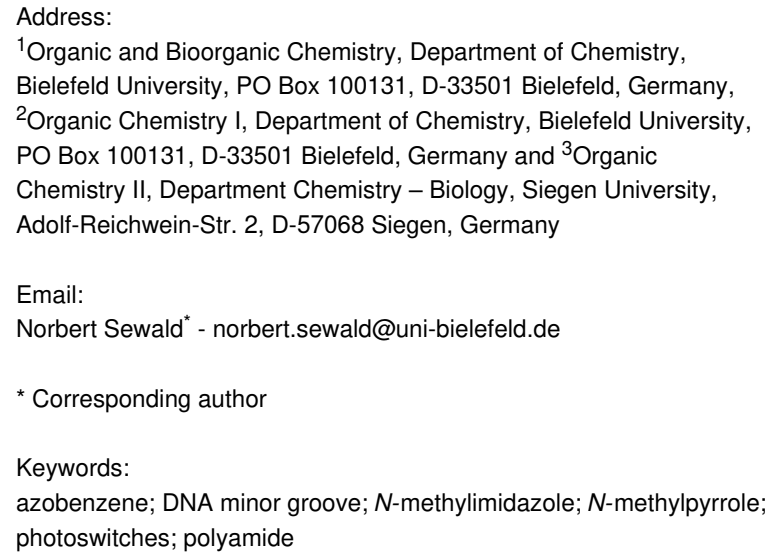

Beilstein J. Org. Chem. 2020, 16, 60-70. doi:10.3762/bjoc. 16.8

Received: 26 October 2019

Accepted: 20 December 2019

Published: 09 January 2020

Associate Editor: K. N. Allen

(C) 2020 Müller et al.; licensee Beilstein-Institut. License and terms: see end of document.

\begin{abstract}
Azobenzenes are photoswitchable molecules capable of generating significant structural changes upon $E$-to- $Z$ photoisomerization in peptides or small molecules, thereby controlling geometry and functionality. $E$-to- $Z$ photoisomerization usually is achieved upon irradiation at $350 \mathrm{~nm}\left(\pi-\pi^{*}\right.$ transition), while the $Z$-to- $E$ isomerization proceeds photochemically upon irradiation at $>400 \mathrm{~nm}$ (n- $\pi^{*}$ transition) or thermally. Photoswitchable compounds have frequently been employed as modules, e.g., to control protein-DNA interactions. However, their use in conjunction with minor groove-binding imidazole/pyrrole ( $\mathrm{Im} / \mathrm{Py}$ ) polyamides is yet unprecedented. Dervan-type Im/Py polyamides were equipped with an azobenzene unit, i.e., 3-(3-(aminomethyl)phenyl)azophenylacetic acid, as the linker between two $\mathrm{Im} / \mathrm{Py}$ polyamide strands. Only the $(Z)$-azobenzene-containing polyamides bound to the minor groove of double-stranded DNA hairpins. Photoisomerization was exemplarily evaluated by ${ }^{1} \mathrm{H}$ NMR experiments, while minor groove binding of the $(Z)$-azobenzene derivatives was proven by $\mathrm{CD}$ titration experiments. The resulting induced circular dichroism (ICD) bands of the bound ligands, together with the photometric determination of the dsDNA melting temperature, revealed a significant stabilization of the DNA upon association with the ligand. The (Z)-azobenzene acted as a building block inducing a reverse turn, which favored hydrogen bonds between the pyrrole/imidazole amide and the DNA bases. In contrast, the $E$-configured polyamides did not induce any ICD characteristic for minor groove binding. The incorporation of the photoswitchable azobenzene unit is a promising strategy to obtain photoswitchable Im/Py hairpin polyamides capable of interacting with the dsDNA minor groove only in the $Z$-configuration.
\end{abstract}




\section{Introduction}

The development of small chemical agents to modulate gene expression in an organism has attracted considerable interest in molecular medicine [1]. However, the missing selectivity of chemical agents, such as chemotherapeutics, often results in undesirable cytotoxicity, harming healthy cells, and thereby inducing a multitude of side effects. A major breakthrough concerning selective small DNA-targeting molecules was the use of pyrrole/imidazole hairpin polyamides. They are conceptually derived from the natural products netropsin and distamycin A, which selectively bind to particular sequences of the DNA duplex [2-4]. Covalent tethering of two antiparallel polyamide segments increases the sequence specificity and the affinity of the polyamides to their cognate dsDNA. Different linker strategies were used, with $\gamma$-aminobutyric acid $(\gamma)$ being the most successful representative. The resulting hairpin polyamides bound with 100-fold higher affinity than the corresponding untethered moieties, with the reverse turn module showing selectivity for AT base pairs [5]. The reason for this selectivity was the steric repulsion with the exocyclic amino function of guanine that pointed inside the DNA groove [2]. The group of Dervan has systematically increased the number of binding motifs, and thus achieved sequence-specific binding [6-9] Selectively binding polyamides adopt an antiparallel hairpin structure where a base pair of the DNA is addressed by a pair of the heterocyclic amino acids in the hairpin assembly. Overall, specific binders have been developed for all possible base pairings (AT, TA, GC, CG; 'pairing rules'). A GC pair is specifically being addressed in the minor groove by $N$-methylimidazole/ $N$-methylpyrrole $(\mathrm{Im} / \mathrm{Py})$, while AT associates with the pair $N$-methylpyrrole/ $N$-methylhydroxypyrrole $(\mathrm{Py} / \mathrm{Hp})$. The same applies to $\mathrm{CG}(\mathrm{Py} / \mathrm{Im})$ and $\mathrm{TA}(\mathrm{Hp} / \mathrm{Py})$. However, $\mathrm{N}$-methylhydroxypyrrole (Hp) is neither easy to synthesize nor sufficiently stable. In practice, therefore, $\mathrm{Py} / \mathrm{Py}$ is used to address both AT and TA.

Along this line, it is attractive to incorporate a molecular switch for the selective activation of an initially inactive substance, once located at the DNA target, with an external stimulus. Azobenzenes are photoswitchable molecules capable of generating significant structural changes in peptides or small molecules, thereby controlling their geometry and functionality upon irradiation [10-13]. While isomerization of the $E$ - to the $Z$-form usually takes place at $350 \mathrm{~nm}$ irradiation $\left(\pi-\pi^{*}\right.$ transition), the reverse is photochemically induced at $450 \mathrm{~nm}\left(\mathrm{n}-\pi^{*}\right.$ transition) or thermally. The rate of thermal relaxation, inter alia, depends on the substituents, and only derivatives with very slow thermal relaxation are suitable as bi-stable switches.

Azobenzene and other small photoreactive molecules have been employed as ligands to control DNA or RNA assembly by light
[14-20]. Mascareñas et al. reported the first photoisomerizable transcription factor ( $\mathrm{Tf}$ ) that recognized its target sequences by major groove recognition [21,22]. Woolley et al. reported other photoisomerizable Tf mimetics that interacted through the major groove [23,24]. Hybridization of DNA [25-27] or PNA/DNA [28] can be light-controlled by azobenzene-modified DNA. While DNA covalently modified with azobenzene moieties was proven amenable for the light-induced triggering of transcription [24], photoswitchable polyamides that can act as selective DNA minor groove binders displaying tunable affinity have not yet been reported $[29,30]$.

We envisaged that control of the geometry and functionality could be achieved upon replacement of the $\gamma$-aminobutyric acid linker between the two hairpin strands by a photoswitchable azobenzene motif. As the azobenzene moiety undergoes a considerable steric reorganization upon isomerization from the $E$ to the $Z$-configuration, the end-to-end distance in a 4,4'-disubstituted azobenzene changes from $9 \AA$ to $5.5 \AA$ upon $E$-to- $Z$ isomerization [31,32]. If we consider the minor groove of double-stranded B-DNA to have a width of approximately $5.7 \AA$ [21], the $Z$-isomer of a 4,4'-azobenzene-tethered Im/Py polyamide would fit into the minor groove, while the two polyamide strands establish direct contacts to the bottom of the cognate minor groove. However, previous studies on distamycin A-like derivatives containing only pyrrole moieties and 4,4'-substituted azobenzene as a photoswitchable linker showed that the binding properties of the $Z$ - and $E$-isomers were quite similar. Hence, there was no switch in binding activity $[29,30]$. Importantly, it was demonstrated that the DNA binding was highly dependent on the linker length between the azobenzene and the distamycin moiety.

\section{Results and Discussion}

Here, we report on the design, synthesis, and characterization of photoswitchable minor groove binders based on pyrrole/imidazole hairpin polyamides functionalized with an azobenzene unit in which the $Z$-isomer is sufficiently stable to allow for accurate measurements. Im/Py polyamides bind to the minor groove of DNA in a sequence-specific manner, encoded by antiparallel side-by-side pairs of pyrrole and imidazole carboxamides with higher binding affinities than the pyrrole analogs alone [33,34]. We selected 3-(3-(aminomethyl)phenyl)azophenylacetic acid as the linker between both polyamide strands because it was shown to induce hairpins in peptides upon $E$-to- $Z$ photoisomerization $[35,36]$. According to molecular dynamics calculations, the 3,3'-substituted azobenzenes are more suitable as photoswitchable building blocks to induce a hairpin motif than the 4,4'-substituted correlates [35]. For 3,3'-substituted azobenzenes, the $Z$-form is expected to display higher thermal stability 
than for the 4,4'-substituted correlates, as the substituents are not conjugated to the $\mathrm{N}=\mathrm{N}$ double bond [35,37-39]. Moreover, it was demonstrated that in the case of peptides, only the $Z$-isomer adopts the hairpin conformation. In our setup, this could influence the hydrogen bonding contacts between the pyrrole/imidazole amide with DNA bases, helping to achieve proper shape complementarity only when the system is in the $Z$-configuration. Therefore, this azobenzene represents a promising approach to replace the $\gamma$-aminobutyric acid linker in the Im/Py polyamide systems.

\section{Design and synthesis of photoswitchable polyamides}

From a pool of new azobenzene-containing polyamides, we present the most promising photoswitchable representatives containing six or eight Im/Py units (P1, P2, and P3, Scheme 1). Their binding capability to dsDNA was analyzed by titration and temperature-dependent circular dichroism experiments.

The assembly of the photoswitchable pyrrole/imidazole polyamides (P1-P3) was performed stepwise on solid phase using the acid-labile 2-chlorotrityl resin and Fmoc as a temporary protecting group, according to the synthetic route published by the Dervan group [40]. The synthesis of the Fmoc-protected photoswitchable $\omega$-amino acid 1 (Scheme 2A) was performed based on a procedure by Aemissegger et al. [35]. The $\omega$-amino acid $\mathbf{1}$ was subsequently used in the solid-phase synthesis or for the synthesis of the dimer 7 in solution (Scheme 2B).

The incorporation of $\beta$-alanine as a 'molecular spring' was required because this allowed for an alignment between hydrogen-bonding groups in long polyamides and in the minor groove of DNA [41].

The Fmoc-protected heterocyclic amino acids 2 were obtained from $N$-methylpyrrole and $N$-methylimidazole, respectively (Scheme 2A). The $N$-terminal $N$-methylpyrrole and $N$-methylimidazole units were introduced by employing diamino derivatives 3 (Scheme 2A) [40]. Moreover, it turned out that coupling the subsequent building block to an $N$-terminal Im building block was problematic because the amino group of the imidazole derivative $\mathbf{2 b}$ is a weak nucleophile, and therefore the Fmoc-Py-Im-OH dimer 5 was obtained [42,43]. Owing to the poor coupling results of Fmoc-Py-OH to the amino function of a terminal Im moiety, the Fmoc-Azo-Im-OH dimer 7 was synthesized in $73 \%$ yield by coupling to the amine 4 , as shown in Scheme 2B.

HBTU as a coupling reagent and DIPEA as a base were employed in DMF for the synthesis of P2. However, in the case of $\mathbf{P 1}$ and P3, the formation of tetramethylguanidinium side prod- ucts was detected by MALDI-TOF MS. This irreversible $\mathrm{N}$-guanylation of the polyamide $\mathrm{N}$-terminus resulted from slow carboxy activation of the building block by HBTU and the presence of an excess of HBTU and could not be completely prevented $[44,45]$. Since this side reaction did not occur with phosphonium salts, P1 and P3 were successfully obtained by using PyBOP as an activating reagent $[45,46]$. After final Fmoc cleavage, the polyamides were released from the resin with a solution of $2.5 \%$ TFA in dichloromethane. The free $C$-terminus of the polyamides was modified in solution with $N, N$-dimethylaminopropylamine by using $\mathrm{PyBOP}$ as an activating reagent to install the corresponding end group. The completeness of all reaction stages was checked by MALDI-TOF MS. Purification of the final products by preparative reversed-phase HPLC gave the TFA salts of the polyamides P1, P2, and $\mathbf{P 3}$ in $10 \%, 2 \%$, and $6 \%$ yield, respectively (see Experimental section).

\section{$E$-to-Z photoconversion}

The functional properties and photoconversion of 3-(3-(aminomethyl)phenyl)azophenylacetic acid were already established previously [35,36,39]. NMR spectroscopy was employed to quantify the photoconversion of the azobenzene-containing polyamides P1-P3 as well as the stability of the Z-isomer. For this purpose, two proton signals were selected, which were not superimposed by other signals and where the chemical shift changed as a result of the switching process. The amide proton of the azobenzene moiety at $8.7 \mathrm{ppm}$ and the adjacent methylene group at $4.5 \mathrm{ppm}$ met these requirements, and hence were used for analysis (Figure 1). The proportions of the individual species in the mixture were determined by integration of the corresponding signals. A representative series of spectra is presented in Figure 1 for polyamide P1. In the thermal equilibrium, approximately $6 \%$ of the $Z$-isomer was present (Figure 1A).

Upon irradiation at $350 \mathrm{~nm}$, this fraction steadily increased and reached a level of $65 \%$ after 50 min irradiation (Figure $1 \mathrm{~B}$ and Figure 1C). However, the $Z$-isomer content could not be increased further by UV irradiation. The $Z$-isomer could subsequently be switched back to the $E$-isomer (19\% Z-configuration after $30 \mathrm{~min}$ ) by irradiation at $420 \mathrm{~nm}$ (Figure 1D). The thermal conversion to the $E$-isomer in the dark was slow at room temperature, and even after 18 days, $13 \%$ of the $Z$-isomer were still present. The thermal equilibrium ( $5 \% Z$-configuration) was reached only after 40 days in the dark (data not shown).

In a previous study, the same azobenzene species incorporated in a hairpin peptide reached a photostationary state of $85 \%$ $Z$-isomer [35]. The photostationary state depends on the nature of the azobenzene, but also on the concentration, as the azobenzene is known to form supramolecular assemblies at high con- 


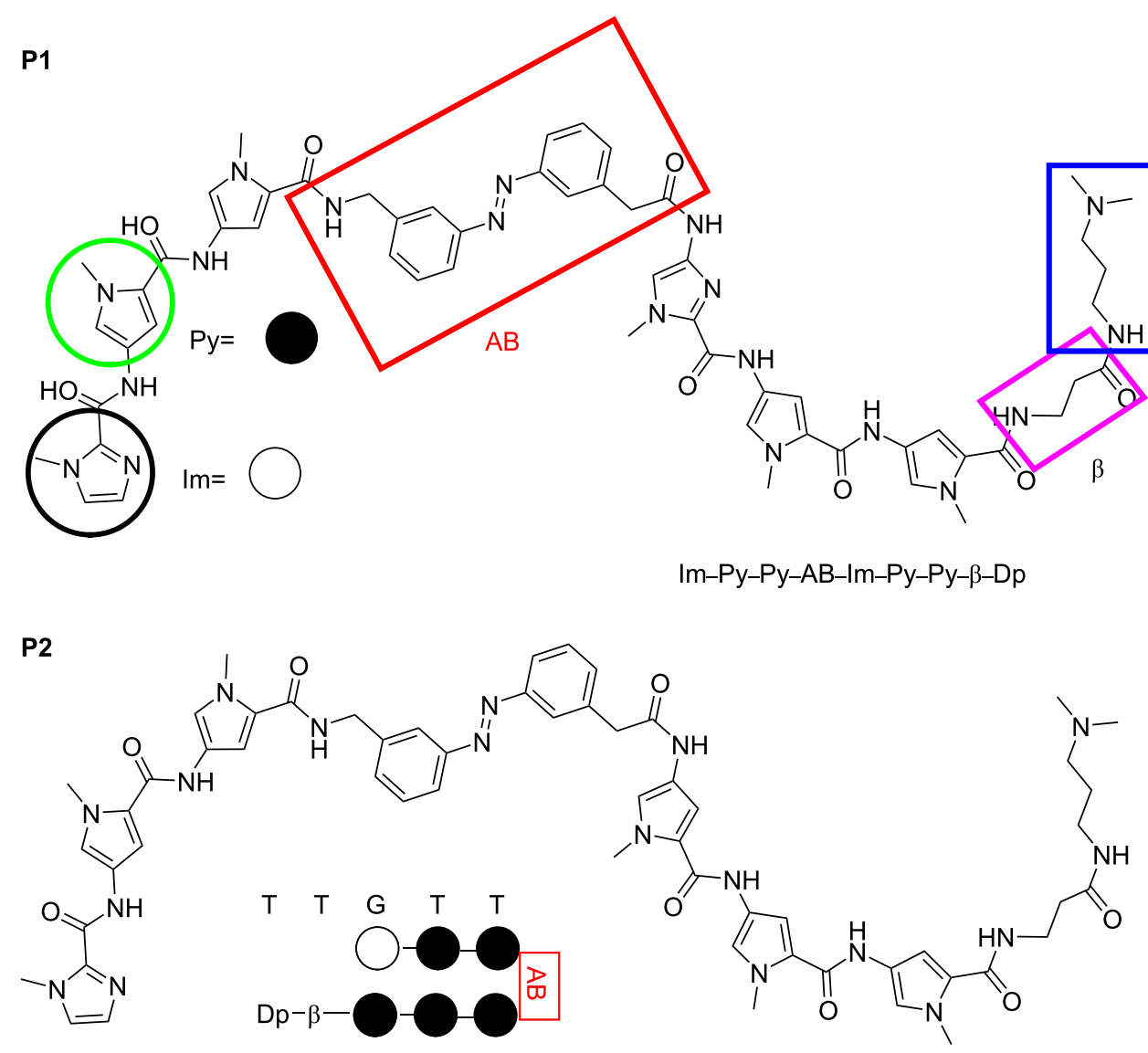

A A $C$ A A Im-Py-Py-AB-Py-Py-Py- $\beta$-Dp

P3<smiles></smiles>

Scheme 1: Pyrrole-imidazole-azobenzene polyamides and the dsDNA target sequences employed in this study.

centration, compromising photoconversion $[11,12]$. When the concentration of polyamide $\mathbf{P 1}$ was reduced to $0.8 \mathrm{mM}, 80 \%$ of the $Z$-isomer were obtained after 15 min of irradiation (Figure 2). In the case of $\mathbf{P 2}$ and $\mathbf{P 3}$, similar results were obtained, and the photostationary $Z$-state $(83 \%$ and $80 \%$, respec- tively) was reached after 15 min irradiation at $350 \mathrm{~nm}$. It has been reported that the $E$-to- $Z$ isomerization of 3,3'-substituted azobenzene compounds proceeds substantially slower than for 4,4'-substituted azobenzene analogs [36]. Moreover, the solutions were kept in the dark to evaluate the thermal stability of 


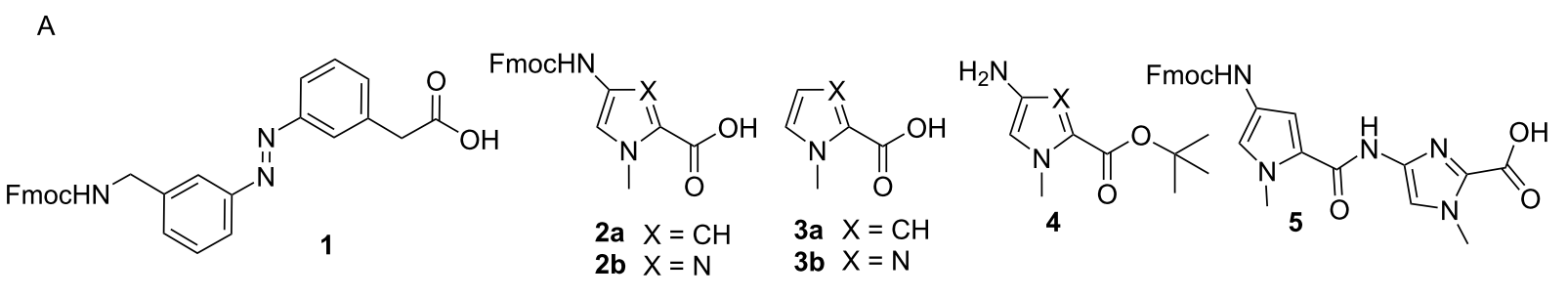

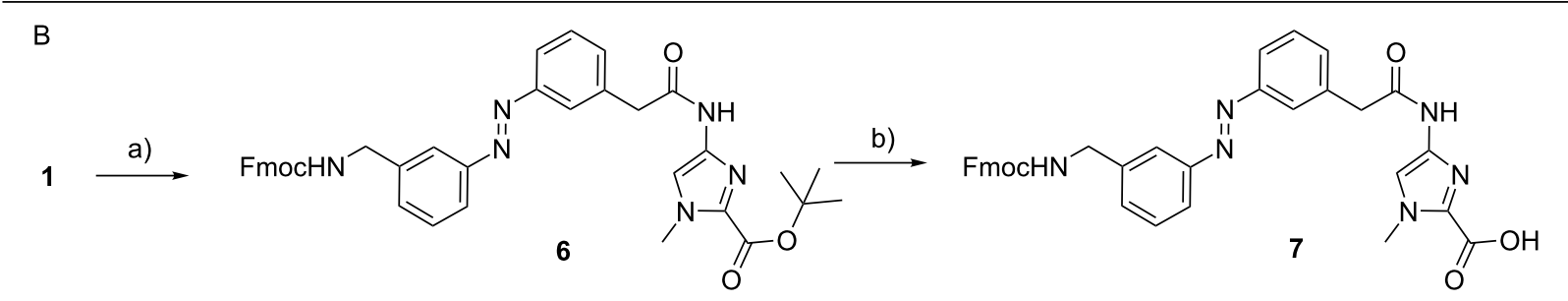

Scheme 2: Building blocks required for the synthesis of the photoswitchable Im/Py polyamides. A) Fmoc-Azo-OH 1, $N$-methylpyrrole and $N$-methylimidazole monomers 2-4, and Fmoc-Py-Im-OH 5. B) Synthesis of the dimer Fmoc-Azo-Im-OH 7: a) DCC, THF, rt, $5 \mathrm{~min}$, then 4, rt, $15 \mathrm{~h}, 41 \%$; b) $\mathrm{BF}_{3} \cdot \mathrm{Et}_{2} \mathrm{O}$, dichloromethane, $0{ }^{\circ} \mathrm{C} \rightarrow \mathrm{rt}, 12 \mathrm{~h}, 73 \%$.
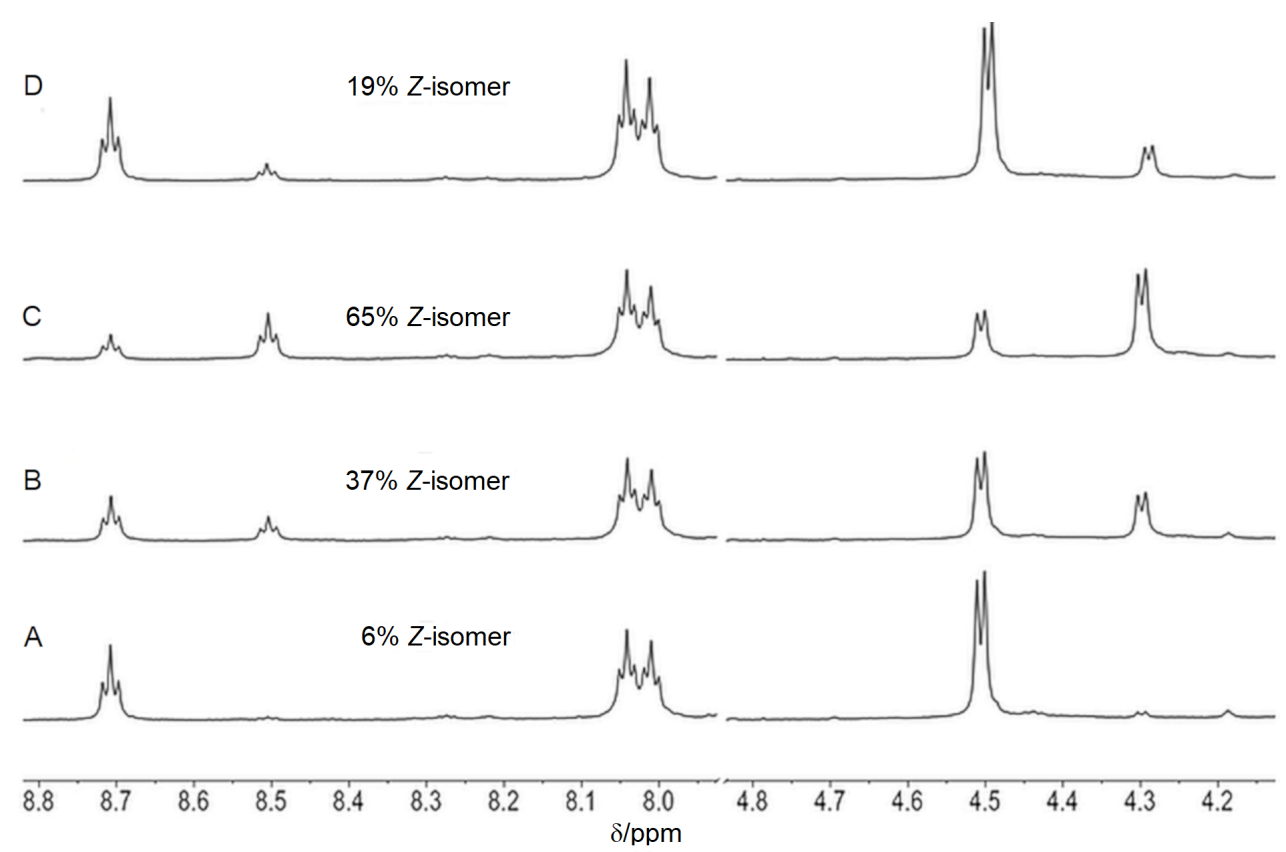

Figure 1: Section of the ${ }^{1} \mathrm{H}$ NMR (600 MHz) spectrum of polyamide P1. A) Initial thermal equilibrium. B) After irradiation at $350 \mathrm{~nm}$ for $10 \mathrm{~min}$. C) After irradiation at $350 \mathrm{~nm}$ for $50 \mathrm{~min}$. D) After irradiation at $420 \mathrm{~nm}$ for $30 \mathrm{~min}$ (in DMSO-d,$c=8 \mathrm{mM}$ ).

the $Z$-isomer, and it was noted that after one or two days, the percentage of $Z$-isomer was slightly reduced (after 2 d: $62 \% \mathbf{P 1}$; 67\% P2; after 1 d: $76 \%$ P3).

\section{Analysis of polyamide-DNA interaction by in- duced circular dichroism}

$\mathrm{CD}$ spectroscopic analysis is suitable for the characterization of DNA minor groove binders, providing semiquantitative information about binding affinity and thermal stability of the target
dsDNA [47-49]. The B-DNA has a positive CD band at 260-280 nm and a negative band at about $245 \mathrm{~nm}$ [47]. In contrast, achiral ligands, such as the polyamides, do not give a CD signal. However, by associating the achiral ligand with chiral DNA, an induced circular dichroism (ICD) signal can be detected at wavelengths longer than $300 \mathrm{~nm}$ where dsDNA does not absorb. Therefore, the occurrence of ICD is a strong indication of the interaction between ligand and DNA [50,51]. This ICD signal originates from the coupling of the transition dipole 


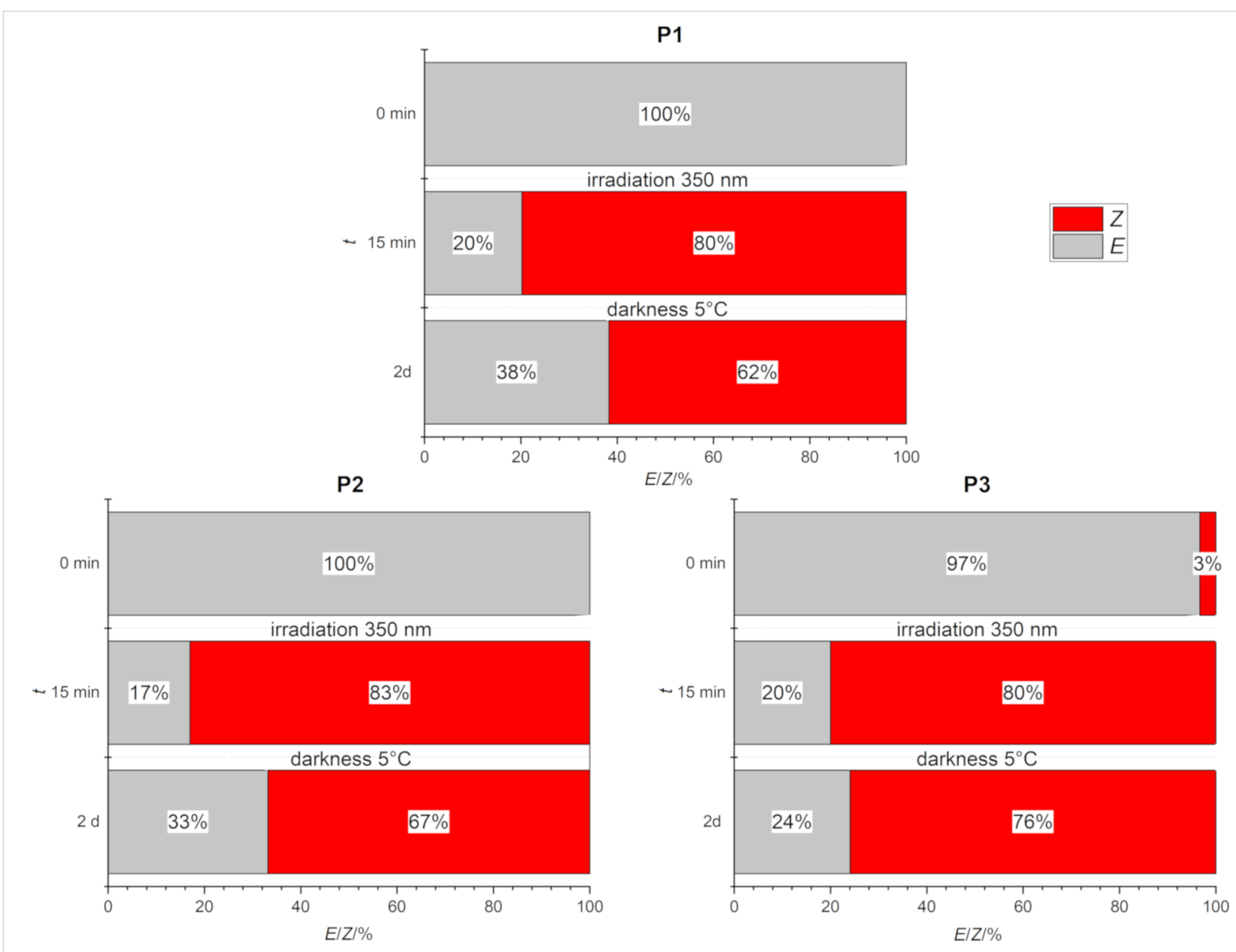

Figure 2: $E / Z$ isomer ratio of the polyamides $\mathbf{P 1 - P 3}$. Values were obtained from the respective ${ }^{1} \mathrm{H}$ NMR experiments $(c=0.80 \mathrm{mM})$ after irradiation $(\lambda=350 \mathrm{~nm}, t=15 \mathrm{~min})$ followed by evaluation after one or two days at $5^{\circ} \mathrm{C}$ in the dark. For details, see Supporting Information File 2 .

moments of the nucleobases and the ligand and is usually positive for polyamide groove binders on B-DNA at about $335 \mathrm{~nm}$ [47,52]. Initially, it was difficult to predict, which sequences would be optimal for the new polyamides containing the azobenzene linker. Hence, we employed the target sequences for the Im/Py hairpin polyamides based on Dervan's pairing rules, such as 5'-TTGTC-3' for P1, 5'-TTGTT-3' for P2, and 5'-TTGTCA-3' for P3 (Scheme 1). Furthermore, as proof of concept, short hairpin oligonucleotide sequences were employed to investigate the interaction of the polyamides with dsDNA because six- and eight-membered polyamides can only bind in a $1: 1$ mode, and thus simplify the analysis $[41,42,47]$. Figure 3 demonstrates that only $(Z)$-polyamides show the characteristic positive ICD signal with the dsDNA sequences tested. The position of the maximum of the positive ICD signal increased with the length of the polyamide (Z-P1 and Z-P2: $\lambda_{\max }=325 \mathrm{~nm} ; Z-\mathbf{P 3}: \lambda_{\max }=333 \mathrm{~nm}$ ), and a new negative band at 280-310 nm was observed, too. The intensity of these new signals increased with increasing concentration of the polyamides. Titrations were performed at molar ratios
PA:hairpin DNA from 0 to 4.8 , where saturation was reached for $Z$-P1 and $Z$-P3 at the ratio 1:3.3. Considering that only the 1:1 PA:dsDNA binding mode was possible for our setup, the observed behavior was indicative of dynamic binding at the concentration tested. Furthermore, for these compounds, hyperchromicity (increase in signal intensity) and hypsochromic shifts of the B-DNA maximum at $\approx 275 \mathrm{~nm}$ and minimum at $\approx 250 \mathrm{~nm}$ were detected upon addition of polyamide.

Considering that PAs do absorb light at wavelengths $<300 \mathrm{~nm}$, the observed changes cannot be unambiguously attributed to the DNA because the ICD of the PA is combined with the intrinsic CD spectrum of the oligonucleotide. Nevertheless, the hyperchromicity of the signal on increasing PA concentration and the spectral behavior observed were characteristic for a B-DNA structure [51,53].

In contrast, Z-P2 did not reach saturation in the tested concentration range (Figure $3 \mathrm{~B}$ ), which is indicative of a lower binding affinity in comparison with the other PAs. For Z-P2, 

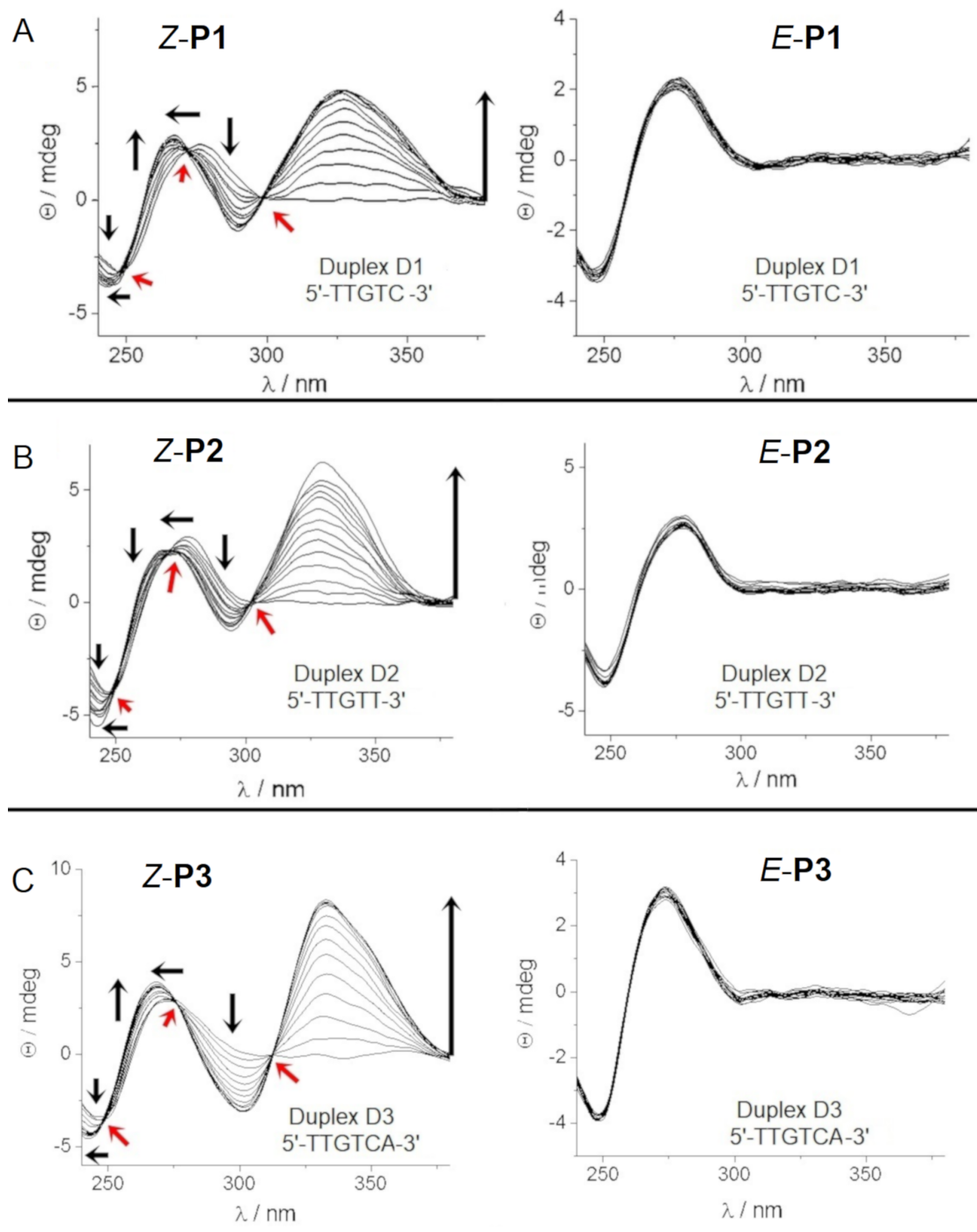

Figure 3: Titration experiments of target DNA sequences with P1-P3 in the photostationary Z-state and the thermal $E$-state. See Table 1 for the complete sequences.

hypsochromic shifts of the B-DNA maximum at $\approx 275 \mathrm{~nm}$ and the minimum at $\approx 250 \mathrm{~nm}$ upon addition of polyamide were accompanied by slightly reduced hyperchromicity. The appearance of clear-cut isodichroic points in the CD titration (red arrows in Figure 3) suggests the formation of one dominant type of DNA/PA complex, which, together with the positive ICD bands observed at wavelengths $>300 \mathrm{~nm}$, indicate minor groove binding [51,53]. Similar results have been obtained by Wang et al., who evaluated the interaction between hairpin Im/Py PA and short hairpin dsDNA sequences [51-53]. Strikingly, no positive ICD effect on the CD spectrum was observed upon addition of the $E$-configured polyamides to the same dsDNA sequences, which indicates that they did not bind to the minor groove of the short dsDNA. Importantly, no precipitation was observed during the measurement. We hypothesize that only the $(Z)$-azobenzene moiety is able to induce the polyamide hairpin conformation required for binding. We also tested the interaction of the polyamides upon single base mutation in the dsDNA sequences to explore the recognition specificity. Specifically, we tested the sequence 5'-TTGTT-3' for P1, 5'-TTGTC-3' for P2, and 5'-TTGTTA-3' for P3 and obtained essentially similar results. Only the $Z$-isomers were able to bind, while the $E$-isomers did not show any interaction with the DNA minor groove (Figure 4).

While the complexes of Z-P1 and Z-P2 with their target DNA (D1 and D2) and single-point mutation DNA (D1' and D2') had similar ICD spectra, the complex of $Z$-P3 with the single-point mutation DNA D3' showed only a blue shift of the B-DNA maximum at ca. $275 \mathrm{~nm}$, but no shift of the minimum at 

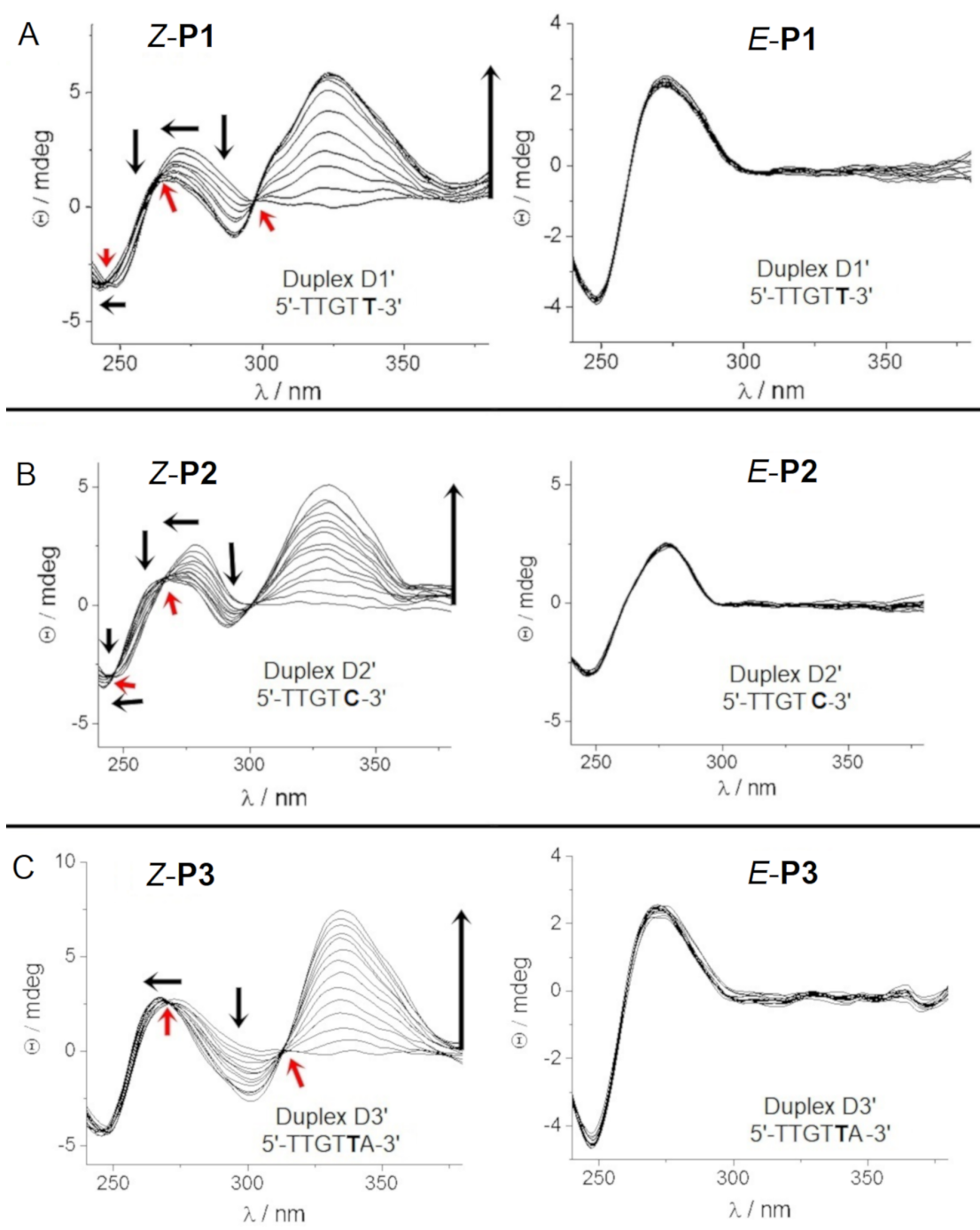

Figure 4: Titration of DNA containing single mutations (in bold) with P1-P3 in the photostationary Z-state and the thermal E-state. See Table 1 for complete sequences.

$\approx 250 \mathrm{~nm}$, lacking this isodichroic point (cf. Figure $3 \mathrm{C}$ and Figure 4C). Finally, Z-P3 did not reach saturation with the single-point mutation DNA D3' at the tested concentration range, suggesting lower binding affinity compared to target dsDNA D3.

The maxima of the ICD signals at 325 and $333 \mathrm{~nm}$ were plotted against the concentration of polyamide to quantify the binding of the PA to the cognate dsDNA. The dissociation constants $K_{\mathrm{D}}$, calculated from the binding isotherms, were in the micromolar range $(11.8 \pm 6.0-52.9 \pm 29.6 \mu \mathrm{M})$. The binding affinity decreased in the order $\mathbf{P 1}>\mathbf{P 3}>\mathbf{P 2}$ for the target sequences and $\mathbf{P 1}>\mathbf{P 2}>\mathbf{P 3}$ for the single-point mutation (Table 1).

The CD spectroscopic experiments indicate that the ligands $E-\mathbf{P 1}-E-\mathbf{P 3}$ did not bind significantly to the oligonucleotide se- quences D1-D3. However, considering their polyamide structure, they should at least exhibt a weak affinity toward doublestranded DNA. The fluorescent indicator displacement (FID) assay was performed with $E$-P1 as representative ligand to examine the propensity of these derivatives to bind to DNA. The known intercalator thiazole orange (TO) was chosen as indicator because it exhibits an intense fluorescence band at $526 \mathrm{~nm}$ when bound to DNA, whereas it is only weakly fluorescent in solution. The displacement of TO from its DNA binding site was monitored by emission spectroscopy. The addition of 2.3 equiv of $E$-P1 led to a displacement of $50 \%$ of TO (cf. Supporting Information File 3), which indicates only a weak binding of $E$-P1 because as a groove binder, the latter occupies more binding sites than TO. These data indicate that E-P1 does bind to DNA in general, but the affinity of this ligand was obviously too low to bind strongly enough to the duplexes D1-D3, 


\begin{tabular}{|c|c|c|c|c|c|}
\hline recognition sequence $\left(5^{\prime} \rightarrow 3^{\prime}\right)$ & $K_{\mathrm{D}} / \mu \mathrm{M}$ & $\begin{array}{l}T_{\mathrm{m} /}{ }^{\circ} \mathrm{C} \\
(\mathrm{DNA})^{\mathrm{a}}\end{array}$ & $\begin{array}{c}T_{\mathrm{m}} /{ }^{\circ} \mathrm{C} \\
(\mathrm{PA} / \mathrm{DNA})^{\mathrm{b}}\end{array}$ & $\Delta T_{\mathrm{m}} / \mathrm{K}$ & PA:DNA \\
\hline \multicolumn{6}{|c|}{ Z-P1 } \\
\hline CATTGTCAGCCTTTTTGGCTGACAATG D1 & $11.8 \pm 6.0$ & 72.2 & 75.7 & 3.5 & 3.3 \\
\hline CATTGTTAGCCTTTTTGGCTAACAATG D1“ & $13.2 \pm 7.8$ & 66.5 & 68.6 & 2.1 & 3.3 \\
\hline \multicolumn{6}{|c|}{ Z-P2 } \\
\hline CATTGTTAGACTTTTTGTCTAACAATG D2 & $52.3 \pm 21.0$ & 65.4 & 67.5 & 2.0 & 3.9 \\
\hline CATTGTCAGACTTTTTGTCDTGACAATG D2، & $42.2 \pm 6.3$ & 68.7 & 70.1 & 1.4 & 3.6 \\
\hline \multicolumn{6}{|c|}{ Z-P3 } \\
\hline CATTGTCATGCCTTTTTGGCATGACAATG D3 & $21.3 \pm 11.2$ & 72.9 & 76.4 & 3.5 & 3.3 \\
\hline CATTGTTATGCCTTTTTGGCATAACAATG D3، & $52.9 \pm 29.6$ & 69.6 & 70.0 & 0.4 & 3.7 \\
\hline
\end{tabular}

${ }^{a_{C}}(\mathrm{dsDNA})=8.87 \mu \mathrm{M}$. ${ }^{\mathrm{b}}$ For the $Z$-isomers, the employed ratio is given. For specific experimental conditions see Experimental section.

as indicated by the lack of any significant induced circular dichroism signal.

We tested the stability of each dsDNA by determining their melting curve during thermal DNA denaturation in the absence or the presence of P1-P3 under otherwise identical experimental conditions for further information on the PA/DNA interaction (see Experimental section). If a polyamide is a minor groove binder, this affects the melting temperature of the dsDNA [34,47,53-55]. The DNA double strand is stabilized by additional hydrogen bonds between ligand and oligonucleotide, and hence the melting temperature is expected to increase. This effect is of particular interest when considering the sequence selectivity of the polyamides, which should therefore also be reflected in a change of the melting temperature. The melting curves after the addition of polyamide were recorded at the highest concentration of polyamide used in the titration experiments (Table 1). Since the hyperchromicity of DNA increases the absorption of ssDNA at $260 \mathrm{~nm}$ compared to that of dsDNA, denaturation can be observed by $\mathrm{CD}$, too. The melting temperature $\left(T_{\mathrm{m}}\right)$ corresponds to the point of inflection where $50 \%$ of the DNA molecules are single-stranded. $T_{\mathrm{m}}$ depends on the number and strength of intramolecular interactions between the single strands, providing information on stabilization or destabilization of the DNA duplex in the presence of the corresponding PA. In general, the more energy needed to break the hydrogen bonds between the single strands of the duplex and the stacking interactions of the bases, the higher the melting temperature. Hence, it also increases with higher GC content. The melting temperature $T_{\mathrm{m}}$ of the dsDNA increased in the presence of the three polyamides Z-P1, Z-P2, and Z-P3, although it is also possible that during heating, thermally induced isomerization to the $E$-isomer occurred (Table 1). The highest stabilization value of the corresponding target sequences was obtained for $Z$-P1 and $Z$-P3 $\left(\Delta T_{\mathrm{m}}=3.5 \mathrm{~K}\right)$. The lowest value was obtained for $Z$-P2 $\left(\Delta T_{\mathrm{m}}=2 \mathrm{~K}\right)$. On the other hand, for the single-point mutation, the $T_{\mathrm{m}}$ values were lower: $\Delta T_{\mathrm{m}}=2.1 \mathrm{~K}$ for Z-P1, $\Delta T_{\mathrm{m}}=1.4 \mathrm{~K}$ for $Z-\mathbf{P 2}$, and $\Delta T_{\mathrm{m}}=0.4 \mathrm{~K}$ for $Z-\mathbf{P 3}$. These results are in agreement with the data of the titration experiments and indicate a higher sequence specificity, e.g., of $Z$-P3. The highest binding affinity (lowest $K_{\mathrm{D}}$ ) was obtained for $Z$-P1, with a slight preference for the target DNA sequence compared to the single mismatch sequence. Binding affinity as well as duplex stabilization was lowest for Z-P2 for both dsDNA sequences tested (Table 1 ). The affinity of $Z$-P3 to the target D3 was twofold higher than to D3' with the single mutation sequence. However, this value is still very much different from the 29-fold selectivity observed for the $\gamma$-Im/Py polyamide analogs of $\mathbf{P 3}$ obtained by DNase footprinting experiments [3]. The DNA sequence selectivity observed for Z-P3 was underlined by an increase of $\Delta T_{\mathrm{m}}=3.5 \mathrm{~K}$ observed for the interaction with the target sequence $\mathbf{D 3}$ compared to $\Delta T_{\mathrm{m}}=0.4 \mathrm{~K}$ for $\mathbf{D 3}$ '.

\section{Conclusion}

We were able to show for the first time that designed heterocyclic polyamides P1-P3, equipped with a photoisomerizable azobenzene, bind to double-stranded DNA hairpins in the $Z$-configuration. In this case, the $(Z)$-azobenzene acted as a building block inducing a reverse turn. Minor groove binding was proven by $\mathrm{CD}$ titration experiments and melting temperature determinations. The $E$-configured azobenzene polyamides did not induce ICD assigned to the polyamide chromophores, possibly because of the formation of small soluble aggregates. Z-P3, with a higher number of heterocyclic units, displayed some sequence specificity, albeit not in a range that was reported for other nonphotoswitchable polyamides. The $(Z)$ azobenzene linker may be sterically more demanding than the $\gamma$-aminobutyric acid linker, which would cause a dilation of the minor groove, and thus reducing the binding affinity and selec- 
tivity of the tested sequences. The previously reported analog of P3 with $\gamma$-aminobutyric acid instead of azobenzene has been used to exert genomic effects on mRNA expression [56]. Therefore, the photoactivation of such interaction may be a future application. The incorporation of the photoswitchable 3-((3(aminomethyl)phenyl)diazenyl)phenylacetic acid linker upon replacement of the $\gamma$-aminobutyric acid linker is a powerful strategy to obtain photoswitchable Im/Py hairpin polyamides capable of interaction with the dsDNA minor groove only in the $Z$-configuration.

\section{Supporting Information}

\section{Supporting Information File 1}

Experimental section.

[https://www.beilstein-journals.org/bjoc/content/

supplementary/1860-5397-16-8-S1.pdf]

\section{Supporting Information File 2}

NMR spectra of P1-P3 and dimers 6 and $\mathbf{7}$.

[https://www.beilstein-journals.org/bjoc/content/

supplementary/1860-5397-16-8-S2.pdf]

\section{Supporting Information File 3}

Photoisomerization of P1-P3 and TO displacement experiments.

[https://www.beilstein-journals.org/bjoc/content/ supplementary/1860-5397-16-8-S3.pdf]

\section{Supporting Information File 4}

HRMS spectra of P1-P3.

[https://www.beilstein-journals.org/bjoc/content/ supplementary/1860-5397-16-8-S4.pdf]

\section{Acknowledgements}

The authors gratefully acknowledge experimental assistance by Anke Nieß and Marco Wißbrock and support by the NMR spectroscopy and the mass spectrometry facilities of Bielefeld University.

\section{Funding}

The authors gratefully acknowledge financial support by the Deutsche Forschungsgemeinschaft (SE609/13-1 and IH24/13$1)$.

\section{ORCID ${ }^{\circledR}$ iDs}

Jochen Mattay - https://orcid.org/0000-0002-1511-7960 Heiko Ihmels - https://orcid.org/0000-0003-0969-0426 Veronica I. Dodero - https://orcid.org/0000-0001-7937-1880 Norbert Sewald - https://orcid.org/0000-0002-0309-2655

\section{References}

1. Rahman, A.; O'Sullivan, P.; Rozas, I. Med. Chem. Commun. 2019, 10, 26-40. doi:10.1039/c8md00425k

2. Mrksich, M.; Parks, M. E.; Dervan, P. B. J. Am. Chem. Soc. 1994, 116, 7983-7988. doi:10.1021/ja00097a004

3. Greenberg, W. A.; Baird, E. E.; Dervan, P. B. Chem. - Eur. J. 1998, 4, 796-805.

doi:10.1002/(sici)1521-3765(19980515)4:5<796::aid-chem796>3.0.co; $2-g$

4. Bhaduri, S.; Ranjan, N.; Arya, D. P. Beilstein J. Org. Chem. 2018, 14, 1051-1086. doi:10.3762/bjoc.14.93

5. Tse, W. C.; Boger, D. L. Chem. Biol. 2004, 11, 1607-1617. doi:10.1016/j.chembiol.2003.08.012

6. Kielkopf, C. L.; White, S.; Szewczyk, J. W.; Turner, J. M.; Baird, E. E.; Dervan, P. B.; Rees, D. C. Science 1998, 282, 111-115. doi:10.1126/science.282.5386.111

7. Dervan, P. B. Bioorg. Med. Chem. 2001, 9, 2215-2235. doi:10.1016/s0968-0896(01)00262-0

8. Dervan, P. B.; Edelson, B. S. Curr. Opin. Struct. Biol. 2003, 13, 284-299. doi:10.1016/s0959-440x(03)00081-2

9. Kielkopf, C. L.; Baird, E. E.; Dervan, P. B.; Rees, D. C. Nat. Struct. Biol. 1998, 5, 104-109. doi:10.1038/nsb0298-104

10. Brieke, C.; Rohrbach, F.; Gottschalk, A.; Mayer, G.; Heckel, A. Angew. Chem., Int. Ed. 2012, 51, 8446-8476. doi:10.1002/anie.201202134

11. Sequeira, M. A.; Herrera, M. G.; Quirolo, Z. B.; Dodero, V. I. RSC Adv. 2016, 6, 108132-108135. doi:10.1039/c6ra20933e

12. Quirolo, Z. B.; Sequeira, M. A.; Martins, J. C.; Dodero, V. I. Molecules 2019, 24, No. 2508. doi:10.3390/molecules24132508

13. Heinrich, B.; Bouazoune, K.; Wojcik, M.; Bakowsky, U.; Vázquez, O. Org. Biomol. Chem. 2019, 17, 1827-1833. doi:10.1039/c8ob02343c

14. Bergen, A.; Rudiuk, S.; Morel, M.; Le Saux, T.; Ihmels, H.; Baigl, D. Nano Lett. 2016, 16, 773-780. doi:10.1021/acs.nanolett.5b04762

15. Dohno, C.; Uno, S.-n.; Nakatani, K. J. Am. Chem. Soc. 2007, 129, 11898-11899. doi:10.1021/ja074325s

16. Dohno, C.; Yamamoto, T.; Nakatani, K. Eur. J. Org. Chem. 2009, 4051-4058. doi:10.1002/ejoc.200900323

17. Basak, A.; Mitra, D.; Kar, M.; Biradha, K. Chem. Commun. 2008, 3067-3069. doi:10.1039/b801644e

18. Wang, X.; Huang, J.; Zhou, Y.; Yan, S.; Weng, X.; Wu, X.; Deng, M.; Zhou, X. Angew. Chem., Int. Ed. 2010, 49, 5305-5309. doi:10.1002/anie.201002290

19. Sánchez, M. I.; Vázquez, O.; Vázquez, M. E.; Mascareñas, J. L. Chem. Commun. 2011, 47, 11107-11109. doi:10.1039/c1cc13355a

20. lqbal, E. S.; Richardson, S. L.; Abrigo, N. A.; Dods, K. K.; Osorio Franco, H. E.; Gerrish, H. S.; Kotapati, H. K.; Morgan, I. M.; Masterson, D. S.; Hartman, M. C. T. Chem. Commun. 2019, 55, 8959-8962. doi:10.1039/c8cc10192b

21. Boga, S.; Bouzada, D.; García Peña, D.; Vázquez López, M.; Vázquez, M. E. Eur. J. Org. Chem. 2018, 249-261. doi:10.1002/ejoc.201700988

22. Caamaño, A. M.; Vázquez, M. E.; Martínez-Costas, J.; Castedo, L.; Mascareñas, J. L. Angew. Chem., Int. Ed. 2000, 39, 3104-3107. doi:10.1002/1521-3773(20000901)39:17<3104::aid-anie3104>3.0.co;20

23. Zhang, F.; Timm, K. A.; Arndt, K. M.; Woolley, G. A. Angew. Chem., Int. Ed. 2010, 49, 3943-3946. doi:10.1002/anie.201000909

24. Morgan, S.-A.; Woolley, G. A. Photochem. Photobiol. Sci. 2010, 9, 1320-1326. doi:10.1039/c0pp00214c 
25. Asanuma, H.; Ito, T.; Yoshida, T.; Liang, X.; Komiyama, M. Angew. Chem., Int. Ed. 1999, 38, 2393-2395. doi:10.1002/(sici)1521-3773(19990816)38:16<2393::aid-anie2393>3.0. co;2-7

26. Liang, X.; Mochizuki, T.; Asanuma, H. Small 2009, 5, 1761-1768. doi:10.1002/smll.200900223

27. Asanuma, H.; Liang, X.; Nishioka, H.; Matsunaga, D.; Liu, M.; Komiyama, M. Nat. Protoc. 2007, 2, 203-212. doi:10.1038/nprot.2006.465

28. Stafforst, T.; Hilvert, D. Angew. Chem., Int. Ed. 2010, 49, 9998-10001. doi:10.1002/anie.201004548

29. Ghosh, S.; Usharani, D.; Paul, A.; De, S.; Jemmis, E. D.; Bhattacharya, S. Bioconjugate Chem. 2008, 19, 2332-2345. doi:10.1021/bc800130u

30. Ghosh, S.; Usharani, D.; De, S.; Jemmis, E. D.; Bhattacharya, S. Chem. - Asian J. 2008, 3, 1949-1961. doi:10.1002/asia.200800151

31. Renner, C.; Kusebauch, U.; Löweneck, M.; Milbradt, A. G.; Moroder, L. J. Pept. Res. 2005, 65, 4-14. doi:10.1111/j.1399-3011.2004.00203.x

32. Wachtveitl, J.; Zumbusch, A. ChemBioChem 2011, 12, 1169-1170. doi:10.1002/cbic.201100185

33. Trauger, J. W.; Baird, E. E.; Dervan, P. B. Nature 1996, 382, 559-561. doi: $10.1038 / 382559 a 0$

34. Chenoweth, D. M.; Meier, J. L.; Dervan, P. B. Angew. Chem., Int. Ed. 2013, 52, 415-418. doi:10.1002/anie.201205775

35. Aemissegger, A.; Kräutler, V.; van Gunsteren, W. F.; Hilvert, D. J. Am. Chem. Soc. 2005, 127, 2929-2936. doi:10.1021/ja0442567

36. Kräutler, V.; Aemissegger, A.; Hünenberger, P. H.; Hilvert, D.; Hansson, T.; van Gunsteren, W. F. J. Am. Chem. Soc. 2005, 127, 4935-4942. doi:10.1021/ja044253u

37. Ulysse, L.; Cubillos, J.; Chmielewski, J. J. Am. Chem. Soc. 1995, 117, 8466-8467. doi:10.1021/ja00137a023

38. Nishimura, N.; Sueyoshi, T.; Yamanaka, H.; Imai, E.; Yamamoto, S.; Hasegawa, S. Bull. Chem. Soc. Jpn. 1976, 49, 1381-1387. doi:10.1246/bcsj.49.1381

39. Dong, S.-L.; Löweneck, M.; Schrader, T. E.; Schreier, W. J.; Zinth, W.; Moroder, L.; Renner, C. Chem. - Eur. J. 2006, 12, 1114-1120. doi:10.1002/chem.200500986

40. Wurtz, N. R.; Turner, J. M.; Baird, E. E.; Dervan, P. B. Org. Lett. 2001, 3, 1201-1203. doi:10.1021/ol0156796

41. Trauger, J. W.; Baird, E. E.; Dervan, P. B. Chem. Biol. 1996, 3, 369-377. doi:10.1016/s1074-5521(96)90120-9

42. Su, W.; Gray, S. J.; Dondi, R.; Burley, G. A. Org. Lett. 2009, 11, 3910-3913. doi:10.1021/ol9015139

43. Wetzler, M.; Wemmer, D. E. Org. Lett. 2010, 12, 3488-3490. doi:10.1021/ol1013262

44. Arttamangkul, S.; Arbogast, B.; Barofsky, D.; Aldrich, J. V. Lett. Pept. Sci. 1997, 3, 357-370. doi:10.1007/bf00127967

45. Albericio, F.; Bofill, J. M.; El-Faham, A.; Kates, S. A. J. Org. Chem. 1998, 63, 9678-9683. doi:10.1021/jo980807y

46. Coste, J.; Le-Nguyen, D.; Castro, B. Tetrahedron Lett. 1990, 31 , 205-208. doi:10.1016/s0040-4039(00)94371-5

47. Dodero, V. I.; Quirolo, Z. B.; Sequeira, M. A. Front. Biosci., Landmark Ed. 2011, 16, 61-73. doi:10.2741/3676

48. Dodero, V. I.; Mosquera, M.; Blanco, J. B.; Castedo, L.; Mascareñas, J. L. Org. Lett. 2006, 8, 4433-4436. doi:10.1021/ol061551i

49. Jiménez-Balsa, A.; Dodero, V. I.; Mascareñas, J. L. Tetrahedron 2013, 69, 7847-7853. doi:10.1016/j.tet.2013.05.126

50. Chang, Y.-M.; Chen, C. K.-M.; Hou, M.-H. Int. J. Mol. Sci. 2012, 13, 3394-3413. doi:10.3390/ijms13033394
51.Šmidlehner, T.; Piantanida, I.; Pescitelli, G. Beilstein J. Org. Chem. 2018, 14, 84-105. doi:10.3762/bjoc. 14.5

52. Qiao, H.; Ma, C.; Zhang, X.; Jing, X.; Li, C.; Zhao, Y. Bioconjugate Chem. 2015, 26, 2054-2061. doi:10.1021/acs.bioconjchem.5b00309

53. Wang, S.; Aston, K.; Koeller, K. J.; Harris, G. D., Jr..; Rath, N. P.; Bashkin, J. K.; Wilson, W. D. Org. Biomol. Chem. 2014, 12, 7523-7536. doi:10.1039/c4ob01456a

54. Lacy, E. R.; Cox, K. K.; Wilson, W. D.; Lee, M. Nucleic Acids Res. 2002, 30, 1834-1841. doi:10.1093/nar/30.8.1834

55. Mergny, J.-L.; Lacroix, L. Oligonucleotides 2003, 13, 515-537. doi:10.1089/154545703322860825

56. Supekova, L.; Pezacki, J. P.; Su, A. I.; Loweth, C. J.; Riedl, R.; Geierstanger, B.; Schultz, P. G.; Wemmer, D. E. Chem. Biol. 2002, 9, 821-827. doi:10.1016/s1074-5521(02)00174-6

\section{License and Terms}

This is an Open Access article under the terms of the Creative Commons Attribution License (https://creativecommons.org/licenses/by/4.0). Please note that the reuse, redistribution and reproduction in particular requires that the authors and source are credited.

The license is subject to the Beilstein Journal of Organic Chemistry terms and conditions: (https://www.beilstein-journals.org/bjoc)

The definitive version of this article is the electronic one which can be found at: doi: $10.3762 /$ bjoc. 16.8 